\title{
The Pink Vans: Bringing Cancer Screening Closer to Home
}

\author{
Frederic Ivan Ting ${ }^{1} \quad$ Louis Mervyn Leones $^{1} \quad$ Jorge Ignacio $^{1}$
}

\author{
${ }^{1}$ Division of Medical Oncology, University of the \\ Philippines - Philippine General Hospital, Manila Philippines
}

Asian J Oncol:2020;6:152-153

Breast cancer is ranked number one in terms of cancer incidence in the Philippines, similar to worldwide statistics. It is also the third most common cause of cancer mortality in the country. ${ }^{1}$

A global survey reported that among 15 Asian countries, the Philippines has the highest breast cancer mortality rate and the lowest mortality-to-incidence ratio. ${ }^{2}$ This may be due to the fact that majority of breast cancers are diagnosed in locally advanced or metastatic stages among low- and middle-income countries (LMICs). Some studies show that in the Philippines more than half (53\%) of patients with breast cancer were diagnosed at stages III and IV, while only 2 to $3 \%$ of cases were treated at stage I.,4 This translates to a dismal $58.6 \% 5$-year survival rate, ${ }^{5}$ much less than worldwide figures.

Studies have described socioeconomic factors as one of the major causes for the lack of access to early detection and treatment. These include lower levels of education, higher poverty rates, inadequate or no health insurance, lack of transportation, or even the unavailability of health services in far-flung areas of the community. ${ }^{6}$ These findings are currently of urgent national concern since the improvements in breast cancer survival rates brought by advances in treatments are mainly dependent on early detection, screening, and timely treatment. ${ }^{7}$

While early detection programs are proven to be cost-effective means for reducing cancer mortality in high-income countries, ${ }^{8}$ initiation and maintenance of these programs are very challenging in LMICs such as the Philippines. Currently, no nationwide breast cancer screening program exists in the country.

In response to this gap in the delivery of services to promote early cancer detection and in line with the Breast Health Global Initiative's call for LMICs to adopt breast cancer screening to the local context, ${ }^{9}$ the University of the Philippines-Philippine General Hospital Cancer Institute (UP-PGH CI) with the help of its donors, established the Mobile Breast Cancer Diagnostic Clinic Program (-Fig. 1), a first in the country. As part of the program, two pink vans that are fully equipped to reach far-flung areas and provide breast cancer screening strategies are sent out to deliver services. These include a clinical breast exam by medical and
Address for correspondence Frederic Ivan Ting, MD, Division of Medical Oncology, University of the Philippines - Philippine General Hospital, Taft Avenue, Manila 1000, Philippines (e-mail: fredtingmd@gmail.com).

surgical oncologists, health education sessions ( - Fig. 2), and diagnostic procedures (e.g., mammography, biopsy of identified suspicious breast masses, basic laboratories, etc.).

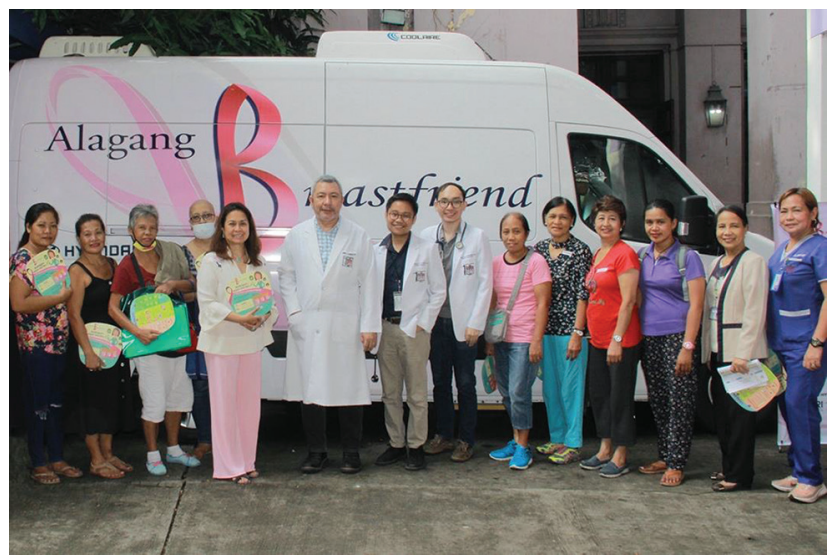

Fig. 1 Dr. Jorge Ignacio (Director, UP-PGH CI), with Medical Oncology Fellows Dr. Lance Catedral and Dr. Alfredo Chua, Jr. (Center) together with stakeholders of the UP-PGH Mobile Breast Cancer Diagnostic Clinic Program.

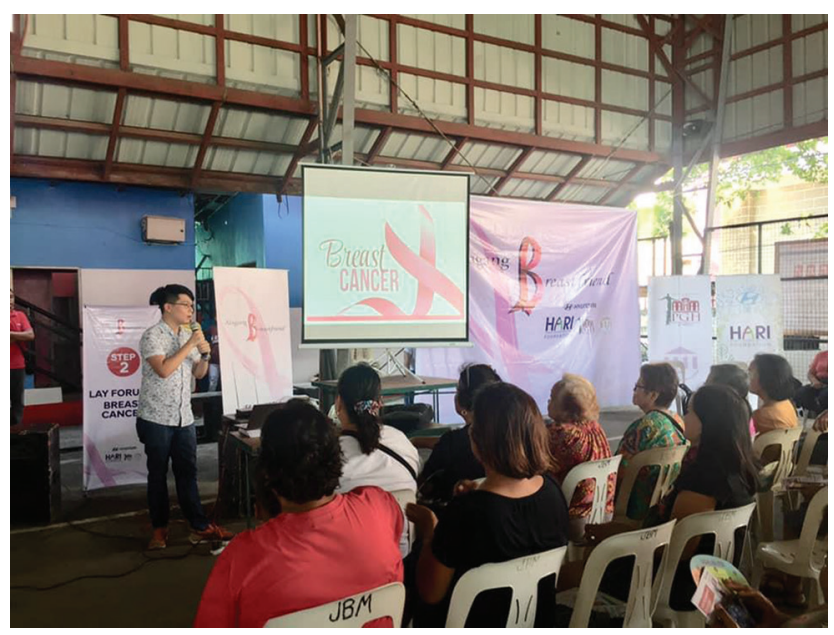

Fig. 2 Dr. Rich King, Chief Fellow of the UP-PGH Division of Medical Oncology (2019), effectively delivers a breast cancer awareness and screening lecture to residents in Ternate, Cavite-most of whom have seen a doctor for the first time. published online June 16, 2020
DOI https://doi.org/

10.1055/s-0040-1713316

ISSN 2454-6798.
License terms

() (1) $\ominus \circledast$ 
In the first 6 months of the program's existence, the pink vans were able to visit three strategically identified areas in the Philippines-Ternate, Cavite; Paco, Manila; and Novaliches, Pampanga. These three tours have served a total of 189 women who all underwent mammography. Of these women, 18 had their suspicious lesions biopsied. Two-thirds of which were found to be malignant. These patients were then referred to our institution for further work-up and management.

Although a formal study has yet to be done to analyze the outcomes of this program, the early results of our Mobile Breast Cancer Diagnostic Clinic Program yielding a 6\% rate of newly diagnosed breast cancer among the total population screened reaffirms the effectiveness and usefulness of this initiative. This is consistent with previous studies which showed that mobile health units used in other countries were found to be effective in improving access and decreasing barriers to screening hard-to-reach populations. ${ }^{10,11}$

As the Philippine health department continues to emphasize clinical and self-breast exam as part of its breast cancer control program, efforts like the UP-PGH "Pink Vans" may eventually help supplement the gap in the country's breast cancer screening endeavors. Ultimately, the main goal of this program is to improve early breast cancer detection rates so cure can be given before it is too late.

\section{Authors' Contributions}

Conceptualization: F.I.T., L.M.L., J.I. Data curation: F.I.T., L.M.L. Formal analysis: F.I.T., L.M.L. Funding acquisition: N/A Methodology: F.I.T., L.M.L. Project administration: J.I. Visualization: J.I. Writing (original draft): F.I.T., L.M.L. Writing (review and editing): F.I.T., L.M.L., J.I.

\section{References}

1 GLOBOCAN. 2018. Available at: https://www.uicc.org/news/ new-global-cancer-data-globocan-2018. Accessed May 25, 2020

2 Pfizer. The burden of cancer in Asia; 2008. Available at: http:// www.pfiz- er.com/files/products/cancersin_asia.pdf. Accessed May 16, 2020

3 De Leon Matsuda ML, Liede A, Kwan E, et al. BRCA1 and BRCA2 mutations among breast cancer patients from the Philippines. Int J Cancer 2002;98(4):596-603

4 Ngelangel CA, Wang EH. Cancer and the Philippine cancer control program. Jpn J Clin Oncol 2002;32(Suppl):S52-S61

5 Laudico A, Redaniel MT, Mirasol-Lumague MR, et al. Epidemiology and clinicopathology of breast cancer in metro Manila and Rizal Province, Philippines. Asian Pac J Cancer Prev 2009;10(1):167-172

6 Pisani P, Parkin DM, Ngelangel C, et al. Outcome of screening by clinical examination of the breast in a trial in the Philippines. Int J Cancer 2006;118(1):149-154

7 van Schoor G, Moss SM, Otten JDM, et al. Increasingly strong reduction in breast cancer mortality due to screening. $\mathrm{Br} \mathrm{J}$ Cancer 2011;104(6):910-914

8 Beaglehole R, Bonita R, Magnusson R. Global cancer prevention: an important pathway to global health and development. Public Health 2011;125(12):821-831

9 Anderson BO, Yip CH, Smith RA, et al. Guideline implementation for breast healthcare in low-income and middle-income countries: overview of the Breast Health Global Initiative Global Summit 2007. Cancer 2008;113(8, Suppl):2221-2243

10 Massin-Short SB, Grullón MA, Judge CM, Ruderman KR, Grullón $\mathrm{M}$, Lora $\mathrm{V}$. A mobile mammography pilot project to increase screening among Latina women of low socioeconomic status. Public Health Rep 2010;125(5):765-771

11 Brooks SE, Hembree TM, Shelton BJ, et al. Mobile mammography in underserved populations: analysis of outcomes of 3,923 women. J Community Health 2013;38(5):900-906

\section{Conflict of Interest}

None declared. 